\title{
La dimensión ambiental del ordenamiento territorial desde el paradigma del desarrollo sostenible en América Latina y en Colombia
}

\author{
The environmental dimension of territorial ordering from the \\ paradigm of sustainable development in Latin America and Colombia
}

Yenny Constanza Román Núñez* y José Luis Farelo Guerra***

Citar este artículo como: Román, Y.C. \& Farelo, J.L. (2016). La dimensión ambiental del ordenamiento territorial desde el paradigma del desarrollo sostenible en América Latina y en Colombia. Revista nodo, 11(21), 95-118.

\section{Resumen}

Este artículo presenta los desarrollos y retos de la inclusión de la dimensión ambiental en el ordenamiento del territorio desde el paradigma del desarrollo sostenible, en algunos países de América Latina, especialmente, en el caso colombiano. Es un estudio descriptivo con métodos cualitativos de la investigación documental (Uribe, 2013), de tipo informativo y de tipo argumentativo (Alfonzo, 1994) para tratar de resolver la siguiente pregunta, ¿cuáles han sido los desarrollos, luego de 26 años del planteamiento inicial desde los países de América Latina de una propia agenda hacia el desarrollo sostenible, como una de las estrategias al ordenamiento del territorio, en especial en el caso colombiano?

Los resultados señalan: que la inclusión de la dimensión ambiental en el ordenamiento territorial está presente en los contenidos de la Carta Europea del Ordenamiento Territorial (1983), que contempló la interrelación hombre-naturaleza, al igual que la dimensión ambiental y social. Esto como consecuencia de la inclusión de la dimensión ambiental en el desarrollo económico en los años 60, producto de las iniciativas del Club de Roma y su informe sobre los Límites del Crecimiento, y posteriormente, con mayor fuerza con el surgimiento del paradigma del desarrollo sostenible. De otro lado, se afirma que el ordenamiento territorial en el caso colombiano está asociado, más que a una única política pública propia sobre el ordenamiento territorial, a un conjunto de políticas públicas sectoriales, principalmente sobre: el desarrollo sostenible (Ley 99 de 1993), el desarrollo económico y social (Ley 152 de 1994), y, el desarrollo territorial y urbano (Ley 388 de 1997), entre otras.

En síntesis el ordenamiento del territorio es un deber del Estado, es una cuestión política y es un asunto de poder, por tanto es necesario, por parte del Estado colombiano, asumir el reto de explorar nuevos enfoques híbridos de políticas (Top down

Fecha de recepción: 11 febrero de 2016 • Fecha de aceptación: 23 septiembre 2016

* Licenciada en Ciencias de la Educación Biología y Química. Especialista en Gestión Ambiental Urbana y magíster en Gestión Urbana. Docente investigadora del Laboratorio de Ambientes Sostenibles Universidad Piloto de Colombia. Contacto: yenny-roman@unipiloto.edu.co

*: Arquitecto especialista en Gerencia de Obras y Planificación Estratégica de Ciudades, magíster en Planeación Urbana y Regional y doctor en Estudios Territoriales. Docente Investigador del Programa de Arquitectura de la Universidad Piloto de Colombia. Contacto: jose-farelo@upc.edu.co 
$y$ bottom up), donde se venzan las divisiones político administrativas del espacio geográfico y posibiliten un ordenamiento sostenible del territorio, el cual debe propender por la armonización de la dimensión natural, social y económica, y que muy seguro, en la práctica serán tangibles a través de las figuras propuestas en la LOOT (Ley 1454 de 2011).

Palabras clave: Dimensión ambiental, Ecodesarrollo, Desarrollo sostenible, Ordenamiento territorial, Ordenamiento ambiental territorial, Conflictos socio-ambientales.

\section{Abstract}

This article presents the development and challenges of the inclusion of the environmental dimension in regional planning from the paradigm of sustainable development, in some Latin American countries, especially in the Colombian case. It is a descriptive study with qualitative methods of documentary research (Uribe, 2013), for informative and argumentative (Alfonzo, 1994) to try to resolve the question: ¿What have been the developments, after 26 years of initial approach from the countries of Latin America Own An Agenda Towards Sustainable Development, as one of the strategies to regional planning, especially in the Colombian case?

The results point out that the inclusion of environmental dimensions in the present, use in the content of the European Charter of Land Management (1983), which looks at the interrelationship between man and nature, like the environmental and social dimension. This as a result of the inclusion of environmental dimensions in the economic development in the 60s, Product Initiatives Club of Rome and its report on the Limits to Growth, and then more strongly with the emergence of the paradigm of Sustainable Development. On the other hand, other states that the use land in the associate Colombian case, own more than a single public policy on land use planning a un joint sectoral public policies, mainly about: sustainable development (Law 99/93) the economic and social development (Law 152/94), and territorial and urban development (Law 388/97), amongst others.

Synthesis and country planning is a duty of the State, which is a matter of policy and a matter of power. Thus, it is necessary, by the Colombian state, to take on the challenge of exploring new hybrid approaches (from top to bottom and bottom-up), where the administrative political divisions of geographical space expire and enable the un sustainable land management. This tends towards harmonization of natural, social and economic dimensions, and is very safe, thus they will be tangible in the practice, through the motions figures in the LOOT (Law 1454/2011).

Keywords: Environmental dimension, Ecodevelopment, Sustainable development, Land management, Environmental land management, Socio-environmental conflicts.

\section{Introducción}

La crisis ambiental es un hecho innegable y de gran relevancia para la permanencia de la humanidad en el planeta, "uno de los retos más grandes para la especie humana en el siglo XXI es la constitución de sistemas de producción y consumo que disminuyan el impacto sobre los recursos naturales y que contemple las dinámicas sociales y, en especial, que no pongan en riesgo la permanencia de la vida humana, así como el equilibrio del organismo vivo llamado planeta Tierra" (Román \& Cuesta, 2016, p. 16). Por tanto, las disciplinas y las ciencias $y$, por extensión las universidades, tienen el compromiso de producir conocimiento que le permita al hombre lograr disminuir el impacto de su estilo de vida e incluso, modificar la lógica civilizatoria que ha producido los problemas ambientales (Elizalde, 2002; Estermann, 2012). "Ya que, más que problemas ambientales, son problemas sociales, lo que implica entender y mejorar la compleja relación hombre-naturaleza" (Román \& Cuesta, 2016, p. 17). 
En la compleja relación hombre- naturaleza, el proceso de adaptación de la especie y humana es la cultura y se realiza a través de la tecnología. Un ejemplo claro de ello, es el manejo de los residuos sólidos, por ejemplo, en Bogotá, la disposición final de los residuos sólidos aún se realiza a cielo abierto, en el relleno sanitario de Doña Juana (Imagen 1), con $450 \mathrm{Ha}$ de extensión ubicado hacia el sur de la ciudad. Mensualmente el relleno recibe 175.915 toneladas de desechos, de los cuales el $64 \%$ son orgánicos y el 36\% son inorgánicos, de estos últimos, los plásticos y cauchos ocupan el segundo lugar con el $18.7 \%$ y, finalmente, en un tercer lugar, se identifican el papel y el cartón con el 8.2\%. (UAESP, 2007). Es decir que a diario llegan más de 6.000 toneladas diarias de residuos con un alto porcentaje de residuos orgánicos. Desde este enfoque tecnológico las soluciones que se proponen desde la gestión ambiental son del orden tecnológico, es decir, plantas de tratamiento de aguas residuales (Imagen 2), rellenos sanitarios, hornos de incineración de residuos. Sin embargo, estos ejemplos evidencian la complejidad de la relación hombre-naturaleza es muy compleja, ya que implica, adicional a las soluciones tecnológicas, procesos preventivos de educación y comunicación que orienten un consumo responsable, así como diferentes instrumentos de planeación que permitan desde el ordenamiento

Imagen 1. Celda a cielo abierto del relleno sanitario Doña Juana, donde se observan las chimeneas que recogen el metano (CH4), producto de la descomposición de los residuos.

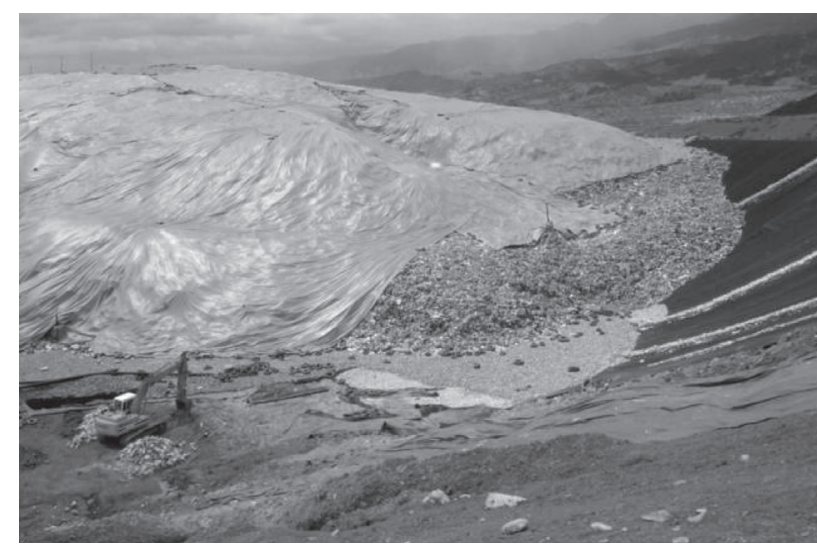

Fuente: fotografía tomada por la autora en 2006.
Imagen 2. Planta de tratamiento de lixiviados transportados por tuberías desde las celdas del relleno de Doña Juana, para luego son vertidos al río Tunjuelo.

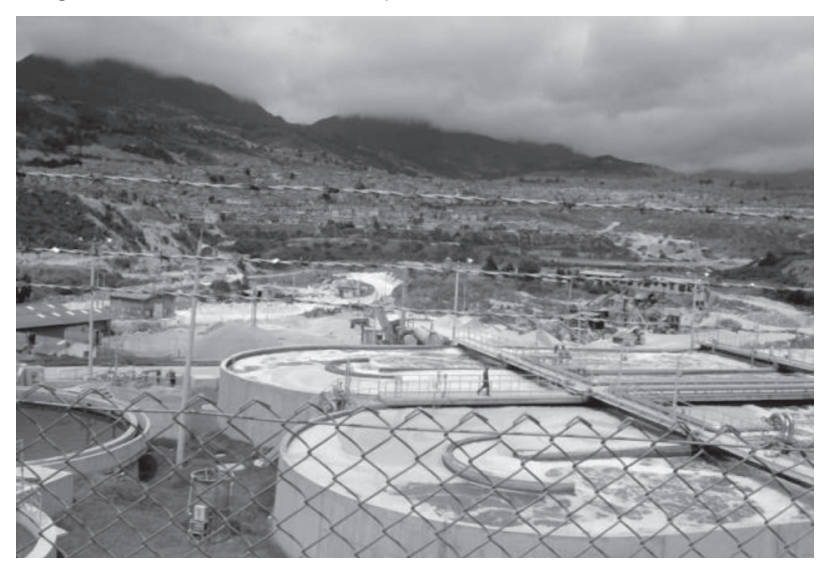

Fuente: los autores.

disponer: de parques de reciclaje, de zonas para rellenos, de grandes zonas para compostaje, o de lugares adecuados para la disposición final de los residuos.

En el mismo sentido, cabe aclarar que esta compleja relación hombre-naturaleza fue abordada inicialmente por las ciencias naturales desde la ilustración como una relación de dominio, en la cual el hombre amo y señor dueño de la creación, dispone de una naturaleza a ser domesticada para su servicio. De ahí que se defina el ambiente como algo externo, lo que rodea un organismo, o "medio". A diferencia del enfoque posterior, dado desde la Ecología, que denomina ambiente como el "sistema o red de relaciones de la que el organismo hace parte” (Camargo, 2005, p. 24), o "ecosistema del cual los seres humanos hacemos parte" (RCFA, 2007, p. 20) y a la misma "Ecología como la ciencia que estudia las relaciones entre los seres vivos y entre estos y su medio" (Odum, 1981, citado por Camargo, 2005, p. 28). Al parecer el concepto de ambiente fue remplazando al de naturaleza; tratando de incluir al hombre dentro de la discusión. Posteriormente, ante las acciones extremadamente conservacionistas, así como debido a la participación de las ciencias sociales y económicas, se migra rápidamente al paradigma de la sostenibilidad; agregando a la dimensión naturalambiental, la dimensión social y económica, 
como dimensiones del desarrollo sostenible. Es importante aclarar estos conceptos y su orden de aparición, ya que dependiendo de la idea que se tenga de ellos son el reflejo de nuestras acciones y propuestas.

Por tanto, dentro de estas aclaraciones es pertinente recordar, que el desarrollo sostenible es definido como "el desarrollo que busca satisfacer las necesidades de las generaciones presentes, sin comprometer la capacidad de las generaciones futuras para compensar las propias" (UN, 1987). Este concepto fue propuesto por primera vez en la Comisión Brundtland por Naciones Unidas en el informe Nuestro Futuro Común, en 1987, en el cual se demanda un cambio urgente de estilo de vida y de producción para paliar el sufrimiento humano y el daño ecológico incrementado en los últimos 200 años desde la industrialización. Ya que, en ese mismo tiempo la velocidad de producción de conocimiento ha aumentado y se ha transitado entre múltiples términos y concepciones; usados a veces como sinónimos sin serlo, o remplazando uno por otro tan rápido, que el común de la sociedad no alcanza ni asimilarlos; de los cuales cabe señalar: naturaleza, medio, ambiente, desarrollo sostenible y ahora se asumen nuevos retos hacia la sostenibilidad o hacia la sustentabilidad.

$\mathrm{Al}$ respecto, en 2015 se dieron varios hechos relevantes en el mundo. En primer lugar, se presentó por parte de Naciones Unidas el cierre y balance de los Objetivos del Milenio (ODM), de 2005 a 2015, donde los países reportaron sus avances en el cumplimiento frente a las metas propuestas para cada objetivo. En segundo lugar, Unesco presentó el balance de la Década de la Educación para el Desarrollo Sostenible de 2004 a 2015. No obstante, la Organización de los Estados Iberoamericanos -OEI reconoció que los graves problemas socio ambientales que fomentaron estas iniciativas siguen agravándose: el agotamiento de los recursos, la pérdida de biodiversidad y de ecosistemas, la contaminación, la mayor producción de residuos y de gases
Imagen 3. Vivienda en altura en el contexto rural de la localidad de Usme, Bogotá.

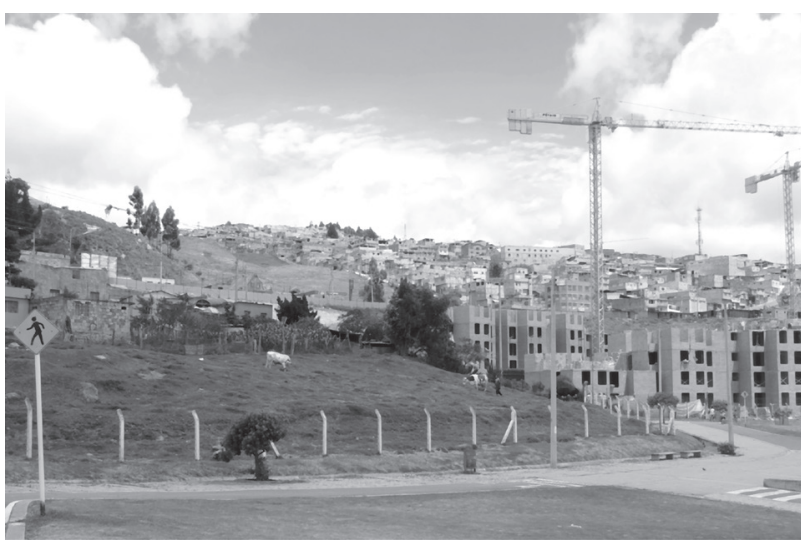

Fuente: fotografía tomada por la autora en 2015.

efecto invernadero, los procesos de urbanización desordenada, la pobreza extrema, el hambre y los desequilibrios sociales; entre otros (OEI, 2013, Párrafo 1).

Recientemente, UN lideró el proceso de formulación y aprobación de los 17 Objetivos del Desarrollo Sostenible 2015-2030, dentro de los cuales se contempla el $O D S$ 11: Lograr que las ciudades y los asentamientos humanos sean inclusivos, seguros, resilientes y sostenibles. Al mismo tiempo, el objetivo contempló la "Meta 11.3. Para 2030 aumentar la urbanización inclusiva y sostenible y la capacidad para lograr una planificación y gestión participativas, integradas y sostenibles de los asentamientos humanos en todos los países" (UN, 2015, p. 25). Sin embargo, varios programas de vivienda en las ciudades colombianas están siendo cuestionados, ya que distan de tener coherencia con el contexto en el que se implantan, como se observa en la Imagen 3.

En este sentido, Naciones Unidas habló de sentar las bases de una transición mundial hacia a la sostenibilidad. Al respecto, propone "la nueva ciencia de la sostenibilidad, para un nuevo periodo de la historia de la humanidad el Antropoceno ${ }^{1}$, que busca

1 El Antropoceno, es un término en construcción propuesto en el año 2000 por Paul Crutzen para remplazar la actuaL época del Holoceno, del periodo Cuaternario de tiempo terrestre, debido a las grandes trasformaciones 
comprender las interacciones entre la naturaleza y la sociedad y favorecer a ambas" (OEI, 2013: párrafo 3, citado por Román, 2016a, pp. 56-57).

Desde luego, la inclusión de la dimensión ambiental en la planificación del desarrollo presenta antecedentes desde las décadas de los 60, 70 y 80 . Por ejemplo, un hecho significativo de finales de los sesenta e inicios de los setenta, fue el informe presentado por el Club de Roma, ONG creada en 1968 conformada por un grupo de científicos, políticos e investigadores que pusieron de manifiesto su preocupación ante la crisis ambiental planetaria y presentaron su escrito denominado Limites del Crecimiento (editado en 1972), cuya tesis principal es que en un planeta limitado, las dinámicas de crecimiento exponencial (población y producción per cápita) no son sostenibles, es decir un crecimiento cero a la población y a la economía. En el informe se consigna:

Si la industrialización, la contaminación ambiental, la producción de alimentos y el agotamiento de los recursos mantienen las tendencias actuales de crecimiento de la población mundial, este planeta alcanzará los límites de su crecimiento en el curso de los próximos cien años. El resultado más probable sería un súbito e incontrolable descenso, tanto de la población como de la capacidad industrial" [...] "nada puede crecer indefinidamente en un medio finito (Meadows et al., 1972, citado por Mayor, 2009. p. 14).

Frente a este hecho, Naciones Unidas (UN) convocó en junio de 1972 a la Conferencia sobre el Medio Humano realizada en Estocolmo, Suecia. La cual "sentó las bases para avanzar en la comprensión del carácter interdisciplinario y sistémico de los problemas ambientales" (UN, 1972, p. 15).

Dentro de los resultados más importantes en Estocolmo 1972 se destacan: la declaración de 26 principios y 109 recomendaciones sobre los

causada por el hombre los ecosistemas producto de los últimos 200 años desde la industrialización. No obstante otros autores, como William Ruddiman afirman que dicha modificación inició hace 8000 años con la agricutura. derechos y deberes ambientales de la humanidad. Donde varios de los principios y recomendaciones se relacionan con la planificación y ordenación de los asentamientos humanos, la planeación del desarrollo económico orientado a la preservación de los recursos naturales en beneficio de las generaciones presentes y futuras. Así mismo, se registra la creación del Programa de las Naciones Unidas para el Medio Ambiente (PNUMA). De acuerdo con Pierri (2005), la relevancia de esta Conferencia radicó en poner el tema en la agenda política internacional y "porque fue el primer intento de conciliar los objetivos tradicionales del desarrollo con la protección de la naturaleza, y de contemplar los diferentes intereses de los países de la comunidad internacional" (p. 36).

Adicionalmente, la autora argumenta, que la tesis sobre los límites físicos al crecimiento poblacional y económico tiene sus antecedentes en la teoría económica clásica de Thomas Roberth Malthus en el siglo XVIII, cuando publicó su ensayo en 1798, en el que planteaba "que, mientras la población se desarrollaba en progresión geométrica o exponencial, la producción de alimentos tendía a hacerlo en progresión aritmética o lineal, por lo que, en un momento dado, los alimentos resultarían insuficientes, y los salarios llegarían a niveles por debajo del de subsistencia. La única solución sería reducir la natalidad, mediante casamiento tardío y abstinencia, o más efectivamente, por el hambre, las epidemias, pestes y guerras, que disminuirían la población por aumento de la mortandad" (citado por Pierri; 2005, pp. 38-39). En igual sentido, 228 años después se debería agregar las pérdidas humanas por desastres naturales debido a la ubicación de poblaciones o ciudades en zonas de alto riesgo.

De otro lado, durante la primera asamblea de PNUMA celebrada en junio de 1973, en Ginebra, Maurice Strong secretario General de la conferencia y primer director ejecutivo del PNUMA, acuñó el término de ecodesarrollo, que para algunos autores pretendió incluir la dimensión ambiental y social en el desarrollo 
económico (Salinas, 1998, citado por Massiris, 2006; Restrepo, 1976; Cruces, 1997). No obstante, se le atribuye a Ignacy Sash la ampliación del concepto, ya que propuso la organización de las sociedades en función del uso racional de los recursos de sus ecosistemas, a través del uso de tecnologías adecuadas, basadas en el esfuerzo propio, en la recuperación de los valores tradicionales y la autodeterminación (Bifani, 1995, citado por Salinas, 1998, en Massiris, 2006).

Por su parte, lo que buscaba el ecodesarrollo era hacer compatible la economía y la ecología al plantear:

[...]modelos o estilos de desarrollo alternativos, autodeterminados y autocentrados, pensados y construidos desde la óptica de los dominados y desplazados en el orden mundial (o en su defensa), que atendieran las situaciones de pobreza, marginación social, cultural y política". [...] desde una óptica comunitaria y tercermundista el ecodesarrollo emergió en la lucha política por definir un nuevo orden mundial, frente a la idea de los límites del crecimiento y la propuesta de transitar hacia una economía estacionaria divulgadas por el Club de Roma, planteando la propuesta de nuevos "estilos de desarrollo" basados en el potencial ecológico de las diferentes regiones y en las capacidades propias de los pueblos del Tercer Mundo. O sea, para comprender esta propuesta es necesario inscribirla dentro del movimiento a favor de un nuevo orden económico internacional llevado adelante por los países no alineados y avalado por la Carta de Derechos y Deberes Económicos de los Estados, aprobada por la Asamblea General de la ONU en 1974, que ratificaba el derecho de los pueblos del Tercer Mundo a obtener el control de sus recursos económicos (Pierri, 2005, pp. 46-47).

Probablemente la propuesta de Ecodesarrollo no tuvo acogida por ser una iniciativa de los países del tercer mundo presentada en la década de los 70, respecto a la soberanía de sus recursos económicos y naturales, obviamente dicha iniciativa afectaba los intereses de los países desarrollados, por eso rápidamente el ecodesarrollo fue opacado por el desarrollo sostenible liderado por los organismos internacionales UN, ONU, UNESCO, PNUMA. "Este concepto podía ser más aceptable para los economistas ortodoxos, ya que se confundía con el crecimiento o desarrollo autosostenido, la última etapa en la teoría evolucionista de desarrollo económico de Rostow, término que "no tenía relación alguna con la dimensión ambiental" (Gutiérrez \& Gonzáles, 2010, p. 83, citado por Handal et al., 2015, p. 42).

El ecodesarrollo de los setenta ha tenido eco en los fundamentos epistémicos de la denominada Ecología Social (Bookchin, 1992 y 1994, citado por Pierri, 2005, p. 28) y, en menor medida, la economía ecológica, con la que comparte la referencia en la ecología y las críticas a las concepciones económicas dominantes, pero no comparte la tesis de los límites físicos absolutos, ni que la solución se centre en detener el crecimiento. Su propuesta política está volcada a promover una sociedad ecológica mediante la expansión de la vida y los valores comunitarios, que achicaría gradualmente el mercado sustituyendo su lógica, así como la dominación estatal. Se inscribe dentro de esta corriente el llamado ecologismo de los pobres y la preocupación por preservar las culturas tradicionales que serían portadoras de una sabiduría ambiental perdida (Martínez, 1995a, citado por Pierri, 2005, pp. 28-29). Actualmente, estos movimientos están muy presentes en países de América Latina como Ecuador y Bolivia frente a los impactos ambientales y sociales causados por empresas multinacionales.

De otra parte, en 1989 los países de América Latina manifestaron su planteamiento frente al ordenamiento territorial, producto del interés por definir una posición como región frente al desarrollo sustentable y la situación ambiental, la inequidad y la pobreza en el mundo, con el objeto de ser presentada en la Conferencia de Río en el año 1992. 
Precisamente, con el apoyo del Programa de las Naciones Unidas para el Desarrollo (PNUD) y el Banco Interamericano de Desarrollo (BID), se conformó la Comisión ${ }^{2}$ de Desarrollo y Medio Ambiente para América Latina, que preparó el informe: Nuestra Propia Agenda sobre Desarrollo y Medio Ambiente (1990). El documento hace un diagnóstico de la realidad latinoamericana y propone la construcción de una agenda y estrategia propia para el desarrollo sostenible de los países latinoamericanos con siete (7) grandes líneas maestras: 1) La erradicación de la pobreza. 2) El aprovechamiento sostenible de los recursos naturales. 3) el ordenamiento del territorio. 4) El desarrollo tecnológico compatible con la realidad social y natural. 5) Una nueva estrategia económica y social. 6) La organización y movilización social y 7) La reforma del Estado (Massiris, 2002, párrafo 34).

Desde luego, una de las estrategias propuestas por la Comisión para el desarrollo sustentable de América Latina fue el ordenamiento territorial, que se define como: "El camino que conduce a buscar una distribución geográfica de la población y sus actividades, de acuerdo con la integralidad y potencialidad de los recursos naturales, que conforman el entorno físico y biótico, todo ello en la búsqueda de unas condiciones de vida mejores" (Comisión de Desarrollo y Medio Ambiente para América Latina, 1990, citado por Massiris, 2002, párrafo 35).

Así mismo, la Comisión propuso como finalidades del Ordenamiento Territorial en América Latina:

- "Inducir la mejor ubicación de las actividades económicas y sociales con relación al aprovechamiento racional de los recursos naturales.

- Controlar las actividades contaminantes.

2 Se conformó una Comisión con representantes de países como: México, Guatemala, Costa Rica, Colombia, Venezuela, Ecuador, Perú, Guyana y Argentina, patrocinada por el Programa para las Naciones Unidas y el Desarrollo-PNUD y el Banco Interamericano de Desarrollo BID, así como la colaboración de CEPAL y PNUMA.
- Descentralizar y desconcentrar la economía en la búsqueda de un desarrollo regional más armónico.

- Delimitar los fines y usos de la tierra, de acuerdo con su vocación ecológica y la demanda que exista sobre ella.

- Señalar espacios sujetos a régimen especial de protección, conservación o manejo.

- Equipar el territorio con el propósito de habilitarlo para el logro del desarrollo sostenible.

- Proteger las zonas ocupadas contra las amenazas naturales.

- Preservar los monumentos históricos, arquitectónicos y el paisaje" (Comisión de Desarrollo y Medio Ambiente para América Latina, 1990).

Los hechos hasta aquí presentados permiten hacer un balance sobre el paradigma del desarrollo sostenible y su estrecha relación con el ordenamiento del territorio. Asimismo, aspectos como: el modelo de desarrollo económico imperante, las decisiones e iniciativas de las políticas de los Estados, y el impacto de los problemas socio-ambientales influyen sobre la relación aquí planteada. Por consiguiente, surge el interés de indagar sobre ¿cuáles han sido los desarrollos, luego de 26 años del planteamiento inicial desde los países de América Latina, de una propia agenda hacia el desarrollo sostenible, como una de las estrategias al ordenamiento del territorio, en especial en el caso colombiano? Por tanto, el objetivo de este artículo es presentar los desarrollos y retos de la inclusión de la dimensión ambiental en el ordenamiento del territorio desde el paradigma del desarrollo sostenible, en algunos países de América Latina, en especial el caso colombiano.

La investigación documental realizada y la reflexión crítica sobre el balance de la dimensión ambiental del ordenamiento del territorio colombiano, desde la normatividad, la institucionalidad y los aportes de varios autores permitieron concluir que la dimensión ambiental en el ordenamiento territorial en el mundo, se identifica desde los 
contenidos de la primera Carta Europea de Ordenación del Territorio CEOT, la cual contempla la interrelación hombre-naturaleza, al igual que la dimensión ambiental y social como propias del ordenamiento del territorio; y las estrategias de integración, coordinación y participación como objetivos desde un ejercicio político.

Asimismo, en Colombia han permeado las concepciones y lineamientos internacionales y latinoamericanos, tanto del desarrollo sostenible, como del ordenamiento territorial. Por un lado, se identifica una propuesta de lineamientos sobre el Ordenamiento Ambiental Territorial- OAT (Ley 99/93) y por el otro de Desarrollo Territorial (Ley 388/97). El OAT en la práctica se convierte en la exigencia de unas determinantes ambientales relacionadas con: la zonificación del suelo, el manejo de las áreas protegidas y los parques naturales, el manejo de la cuenca, la conservación de los ecosistemas y la definición de las zonas de riesgo natural. Aunque estas determinantes ambientales son muy importantes para el ordenamiento del territorio, es necesario vincular a todos los actores en los procesos participativos y en el ejercicio de definición de políticas bottom up (de abajo hacia arriba), que dinamice la dimensión social y ambiental del ordenamiento territorial.

En síntesis se concluye que el ordenamiento del territorio es un deber del Estado, es una cuestión política y es un asunto de poder, por tanto es necesario, por parte del Estado colombiano, asumir el reto de explorar nuevos enfoques híbridos de políticas (Top down y bottom up), donde se venzan las divisiones político administrativas del espacio geográfico y posibiliten un ordenamiento sostenible del territorio, el cual debe propender por la armonización de la dimensión natural, social y económica, y que muy seguro, en la práctica serán tangibles a través de las figuras propuestas en la LOOT (Ley 1454/2011), como el desarrollo de proyectos conjuntos entorno a un tema común de región y no de municipio, como se profundizará a continuación.

\section{Metodología}

Este estudio descriptivo emplea métodos cualitativos de la investigación documental ${ }^{3}$ (ID), que de acuerdo con Alfonzo (1994), por su naturaleza y profundidad analítica puede ser, de tipo informativo, correspondiente al barrido de fuentes confiables sobre el tema sin un análisis profundo, ya que en primer lugar se indagó sobre la inclusión de la dimensión ambiental del ordenamiento territorial desde el planteamiento del desarrollo sostenible en América Latina. De la misma manera, la ID puede ser de tipo argumentativo, ya que "es esencialmente analítica y trata de probar una hipótesis del investigador o incluso llegar a resolver la pregunta de investigación" (Páramo, 2010, citado por Uribe, 2013, pp. 200-201). Seguidamente, se realizó una reflexión crítica sobre un balance de la dimensión ambiental del ordenamiento del territorio colombiano, desde la normatividad, la institucionalidad y los aportes de varios autores y finalmente se realiza un análisis crítico como contribución a la discusión.

\section{Resultados}

\section{La dimensión ambiental del ordena- miento territorial desde el planteamiento del desarrollo sostenible en América Latina}

Antes de ahondar sobre las concepciones del ordenamiento territorial en América Latina, es necesario considerar de manera general la Carta Europea de Ordenación del Territorio-CEOT

3 Según Uribe (2013), la investigación documental [...] es en esencia el estudio metódico, sistemático y ordenado con objetivos bien definidos, de datos, documentos escritos, fuentes de información impresa, contenidos y referencias bibliográficas los cuales una vez compilados, contextualizados, clasificados, categorizados y analizados, sirven de base para la comprensión del problema, la definición o redefinición de nuevos hechos o situaciones problémicas, la elaboración de hipótesis o la orientación a nuevas fuentes de investigación en la construcción de conocimiento (p. 198).

4 Aprobada el 20 de mayo de 1983 en Torremolinos (España), en la Conferencia Europea de Ministros Respon- 
(1983), que es uno de los primeros textos internacionales que hizo referencia al Ordenamiento del Territorio (OT); en cuanto a su definición, características y objetivos. Este producto de la primera Conferencia Europea de Ministros responsables de la Ordenación del Territorio (CEMAT) $)^{5}$ definió:

La ordenación del territorio como la expresión geográfica de las políticas económicas, sociales, culturales y ecológicas de la sociedad. Es al mismo tiempo una disciplina científica, una técnica administrativa y una política de responsabilidad pública a desarrollar con un enfoque interdisciplinar e integrado y dirigido tanto al desarrollo regional equilibrado como a la organización física del territorio de acuerdo a una estrategia de conjunto (1983, p. 2).

Al respecto Massiris (1999) afirma que "este concepto se reproduce en todos los países europeos adaptado a las condiciones y objetivos específicos de sus políticas nacionales" (párrafo 4). Por su parte, Zoido (1998) afirma que la CEOT no es clara conceptualmente, ya que "confunde los resultados con el instrumento", puesto que la carta define la ordenación del territorio como la expresión espacial de la política económica, social, cultural y ecológica de toda sociedad; el mismo autor afirma que además "complica más las cosas al añadir que es a la vez una disciplina científica, una técnica administrativa y una política" (p. 20).

Ahora bien, en el caso europeo varios autores coinciden en identificar dos enfoques del OT. El primero, el modelo alemán (Raumordnung), que se replica en países como: Austria, Suiza, Holanda, Italia, España y Portugal. Este modelo se enfoca a la planeación física a escala regional, subregional y local; asociado al uso y ocupación del suelo, así como a procesos urbanos, a partir de la coordina-

sables de la Ordenación del Territorio. Esta carta es un documento de siete hojas que circula en la WEB: [http:// titulaciongeografia-sevilla.es/web/contenidos/profesores/ materiales/archivos/Carta_Europea_OT.pdf].

5 La primera conferencia CEMAT se celebró en Bonn, y estableció el foro que reúne cada tres años a los altos funcionarios para trabajar sobre el Ordenamiento del Territorio, labor desempeñada desde los años 70. ción de políticas sectoriales. El segundo modelo, es el caso de Francia (Aménagenent du territorie), que se caracteriza por la "planificación territorial integral vinculada estrechamente a la planificación económica y social, con el objeto de garantizar el equilibrio en el desarrollo regional" (Massiris, 1994, p. 33; Hildenbrand, 2002; Carrión, 2008).

En efecto, Carrión afirma que:

La noción de OT surgió en Alemania y en Francia (Borja, 2000), asociada a intentos de política y planificación que buscaban la solución a problemas de localización industrial, mineras y de aglomeraciones urbanas, derivados de la creciente demanda de viviendas y ausencia de zonas verdes en el caso de Alemania, y a un desarrollo de la planificación centralizada para la localización de actividades económicas e infraestructuras en los años 50 en el caso de Francia (Hildenbrand, 2002, p. 55, citado por Carrión, 2008, p. 146; Caballero, 1997; Hildenbrand, 1996, citado por Salinas, 2013, p. 145).

No obstante, un aspecto relevante de la Carta Europea de Ordenación del Territorio de 1983 es que incluyó como características de la ordenación del territorio la interrelación hombre-naturaleza: "El hombre y su bienestar, así como su interacción con el medio ambiente, constituyen el centro de toda preocupación de la ordenación del territorio, cuyo objetivo es el de ofrecerle un marco y una calidad de vida que aseguren el desarrollo de su personalidad en un entorno organizado a escala humana" (p. 1).

De la misma manera, la CEOT (1983) indica que la ordenación del territorio debe ser democrática, global, funcional y prospectiva; y que además debe perseguir los siguientes objetivos: a) El desarrollo socioeconómico equilibrado de las regiones; b) La mejora de la calidad de vida; c) La gestión responsable de los recursos naturales y la protección del medio ambiente; y d) La utilización racional del territorio (pp. 2-4). Finalmente, la Carta afirma que el desarrollo de los objetivos mencionados son una tarea política y que la "ordenación del territorio es el reflejo de una voluntad de integración 
y de coordinación de carácter interdisciplinario y de cooperación entre las autoridades afectadas" ( $p$. 4). Para lo cual, se deberá: a) garantizar la coordinación entre distintos actores; b) organizar la coordinación entre los diversos niveles de decisión y la distribución equitativa de recursos financieros; y c) garantizar la participación de la población. (pp. 4-5). Como se evidencia en los argumentos aquí presentados, la CEOT contempló desde su origen la interrelación hombre-naturaleza, al igual que la dimensión ambiental y social como propias del ordenamiento del territorio; y las estrategias de integración, coordinación y participación como objetivos desde un ejercicio político.

A continuación, se cita una comparación de conceptos sobre ordenamiento territorial de 14 países realizada por Massiris (2002) (2006), la cual luego fue analizada por Cuervo (2006), como se observa en la tabla 1. Esto con el fin de identificar la inclusión de la dimensión ambiental del ordenamiento territorial desde el planteamiento del desarrollo sostenible en América Latina.

Este análisis le permitió al autor reconocer la diversidad de interpretaciones que responden a las diferentes formas de entender la naturaleza y el objeto de la ordenación, aspecto que se denota en la siguiente afirmación:

Todos ellos llevan explícita o implícitamente la idea de regular u organizar el uso, ocupación y transformación del territorio con fines de su aprovechamiento óptimo. Este aprovechamiento se asocia generalmente con el uso sustentable de los recursos naturales (planificación físicaambiental), en estrecha correspondencia con patrones adecuados de distribución de asentamientos y de actividades económicas (Massiris, 2002).

Tabla 1

Tabla sobre concepciones del ordenamiento del territorio en algunos países latinoamericanos.

\begin{tabular}{|c|c|}
\hline País & Concepto de ordenamiento territorial \\
\hline Argentina & $\begin{array}{l}\text { "Conjunto de acciones técnico político-administrativas para la realización de estudios, la formulación de } \\
\text { propuestas y la adopción de medidas específicas en relación con la organización de un territorio, a fin de } \\
\text { adecuarlos a las políticas y objetivos de desarrollo general establecidos por los distintos niveles jurisdic- } \\
\text { cionales (Nación, Provincia, Municipio) y en concordancia con sus respectivas estrategias. (Provincia de } \\
\text { Buenos Aires, 1977) }\end{array}$ \\
\hline Bolivia & $\begin{array}{l}\text { "Proceso de organización del uso y la ocupación del territorio, en función de sus características biofí- } \\
\text { sicas, ambientales, socioeconómicas, culturales y político-institucionales, con la finalidad de promover } \\
\text { el desarrollo sostenible del país". (Senado Nacional, 2001) }\end{array}$ \\
\hline Colombia & $\begin{array}{l}\text { "Conjunto de acciones político-administrativas y de planificación física concertadas, emprendidas por el } \\
\text { municipio o distritos y áreas metropolitanas ..., parar orientar el desarrollo del territorio bajo su jurisdic- } \\
\text { ción y regular la utilización, transformación y ocupación del espacio, de acuerdo con las estrategias de } \\
\text { desarrollo socioeconómico y en armonía con el medio ambiente y las tradiciones históricas y culturales". } \\
\text { (Congreso de la República de Colombia, 1997). }\end{array}$ \\
\hline Costa Rica & $\begin{array}{l}\text { "Proceso dinámico, interactivo e interactivo de diseño de cambios integrales en las políticas públicas para } \\
\text { la clasificación y el uso racional, eficiente y estratégico del territorio, de acuerdo con criterios económicos, } \\
\text { culturales y de capacidad de carga ecológica y social". (Ministerio de Planificación Nacional, 1998:3) }\end{array}$ \\
\hline Cuba & $\begin{array}{l}\text { "Disciplina técnico administrativa destinada a mejorar las condiciones que tiene el territorio para las } \\
\text { funciones sociales y económicas. Se concreta en los ámbitos nacional, provisional, municipal y urbano y } \\
\text { su contenido fundamental es la estructuración del espacio físico". (Instituto de planificación Física, 2001) }\end{array}$ \\
\hline Chile & $\begin{array}{l}\text { "Acción estatal ejercida consensuadamente, que permite la integración pública y privada orientada a } \\
\text { armonizar los usos del territorio, tanto público como privado, propendiendo a un uso racional y susten- } \\
\text { table del territorio en su más amplio sentido". (CONOMA, 1998) }\end{array}$ \\
\hline
\end{tabular}




\begin{tabular}{|c|c|}
\hline País & Concepto de ordenamiento territorial \\
\hline Ecuador & $\begin{array}{l}\text { "Zonificación económica, social y ecológica del país sobre la base de la capacidad del uso de los ecosis- } \\
\text { temas, las necesidades de protección del ambiente, el respeto a la propiedad ancestral de las tierras } \\
\text { comunitarias, la conservación de los recursos naturales y del patrimonio natural. Debe coincidir con } \\
\text { el desarrollo equilibrado de las regiones y la organización física del espacio. El ordenamiento territorial } \\
\text { no implica una alteración de la división político administrativa”. (Congreso Nacional de Ecuador, 1998). }\end{array}$ \\
\hline El salvador & $\begin{array}{l}\text { "Establecer normas que regulen, promuevan, estimulen y coordinen la eficiente y ordenada utilización } \\
\text { del territorio nacional, haciendo el adecuado uso del suelo para la explotación racional y sostenible de los } \\
\text { recursos naturales" (Asamblea Legislativa, 1998) }\end{array}$ \\
\hline Honduras & $\begin{array}{l}\text { "Establecer un conjunto coherente de normas y principios, que regulen el proceso de ordenamiento } \\
\text { territorial y de los asentamientos humanos, promoviendo la relación armónica entre la población y el } \\
\text { territorio, orientado a la inversión pública y privada, fomentando la optimización del uso de los recursos } \\
\text { naturales renovables y no renovables, para lograr el desarrollo sostenible" (Gobierno de Honduras, 1999). }\end{array}$ \\
\hline México & $\begin{array}{l}\text { "Estrategia de desarrollo socioeconómico que, mediante la adecuada articulación funcional y espacial } \\
\text { de las políticas sectoriales , busca promover patrones sustentables de ocupación y aprovechamiento del } \\
\text { territorio". (SEDESOL y otros, 2000) }\end{array}$ \\
\hline Nicaragua & $\begin{array}{l}\text { "Conjunto de medidas dirigidas a contribuir en la utilización adecuada y planificada de los recursos natu- } \\
\text { rales, distribución de la población, una economía más organizada y articulada, un proceso inversionista } \\
\text { coherente, así como la prevención y mitigación de los desastres naturales". (INTER, 2000) }\end{array}$ \\
\hline $\begin{array}{l}\text { República } \\
\text { Dominicana }\end{array}$ & $\begin{array}{l}\text { Organización y administración racional de "la ocupación y uso del territorio, así como sus recursos natu- } \\
\text { rales, para prevenir y mitigar los efectos ambientales o socio-territoriales que acarrean las actividades } \\
\text { socioeconómicas, a fin de mejorar la calidad de vida de la población y garantizar la permanencia de la } \\
\text { base de sustentación ecológico". (Gobierno de la República Dominicana, 2000) }\end{array}$ \\
\hline Uruguay & $\begin{array}{l}\text { "Conjunto de políticas o directivos expresamente formuladas, normas y programas que orienten y } \\
\text { regulen las actuaciones y procesos de ocupación, desarrollo y transformación del territorio y el uso del } \\
\text { espacio". (Presidencia de la República de Uruguay, 2000) }\end{array}$ \\
\hline Venezuela & $\begin{array}{l}\text { "Regulación y promoción de la localización de los asentamientos humanos, de las actividades económicas } \\
\text { y sociales de la población, así como el desarrollo físico espacial, con el fin de lograr una armonía entre } \\
\text { el mayor bienestar de la población, y la optimización de la explotación y uso de los recursos naturales y } \\
\text { la protección y valorización del Medio Ambiente, como objetivos fundamentales del desarrollo integral". } \\
\text { (Congreso de la República de Venezuela, 1983) }\end{array}$ \\
\hline
\end{tabular}

Fuente: Massiris (2002).

Por su parte, Cuervo (2006) realizó su propio análisis sobre el mismo recuento de los 14 conceptos, permitiéndole establecer las siguientes variantes:

Una primera, en seis países (Argentina, Bolivia, Colombia, Venezuela, México, Honduras) de los 14 casos que se relaciona con el desarrollo (integral, sostenible, socioeconómico).

Una segunda variante en seis países (Chile, Costa Rica, Salvador. Nicaragua, República Dominicana y Ecuador) de los 14 casos, establece que el $O T$ debe hacerse de acuerdo con criterios básicamente ecológicos y ambientales, o aún con una mezcla de éstos últimos con otros de distinto carácter.

En un estudio posterior Massiris observa la ausencia de una unidad de criterio, tanto en la concepción como en los alcances, debido a la diversidad del surgimiento de estas políticas en dichos países. "Se trata, en la mayoría de casos, de una mutación de aproximaciones sectoriales de carácter urbanístico, económico-regional o ambiental, que intenta integrar o articular guiadas por principios de desarrollo sustentable o de protección de los recursos naturales y de recuperación y control de condi- 
ciones ambientales adversas, sin que se logre un ensamblaje apropiado" (2006, p. 42). De la misma manera, el autor enfatiza que "en su instrumentación no existe claridad sobre los mecanismos de articulación necesarios para armonizar las acciones sectoriales y territoriales, ni sobre sus diferencias y complementariedades, lo que lleva a que a menudo el OT se confunda con la planificación ambiental, el urbanismo, la división territorial político-administrativa, la regionalización y la descentralización administrativa. Aún está lejos de concebir el plan de OT como marco orientados de las políticas sectoriales y territoriales".

En tanto que, al analizar los mismos 14 conceptos de ordenamiento territorial de los países latinoamericanos desde una perspectiva de inclusión de la dimensión ambiental desde el paradigma del desarrollo sostenible, se identifican postulados como "la optimización de la explotación y uso de los recursos naturales y la protección y valoración del medio ambiente, como objetivos fundamentales del desarrollo integral" (Venezuela, 1983); "prevenir y mitigar los efectos ambientales o socioterritoriales que acarrean las actividades socioeconómicas" (República Dominicana, 2000); "utilización adecuada y planificada de los recursos naturales [...] prevención y mitigación de los desastres naturales" (Nicaragua, 2000); "promover patrones sustentables de ocupación y aprovechamiento del territorio" (México, 2000); "relación armónica entre la población y el territorio... fomentando la optimización del uso de los recursos naturales renovables y no renovables para lograr el desarrollo sostenible" (Honduras,1999); "explotación racional y sostenible de los recursos naturales" (Salvador, 1998); "armonizar los usos del territorio[...]propendiendo a un uso racional y sustentable del territorio[...]" (Chile, 1998); "uso racional eficiente y estratégico del territorio de acuerdo con [...] capacidad de carga ecológica y social" (Costa Rica, 1998); "desarrollo del territorio en armonía con el ambiente [...]" (Colombia, 1997); "uso y ocupación del territorio [...], con la finalidad de promover el desarrollo sostenible del país" (Bolivia, 2001).
Desde luego, estas posturas son respuestas claras de los países de América Latina en la concepción del ordenamiento del territorio desde el planteamiento del desarrollo sustentable, propuesto a finales de la década de los 80s, las cuales tratan de abordar de una u otra manera, en mayor o menor alcance, las dimensiones económica, social y ambiental del desarrollo sostenible. Aunque, el caso de Venezuela es diferente, ya que fue el primer país en definir su ordenamiento territorial, previo a la propuesta del desarrollo sostenible, según los años reportados en la tabla, pero posiblemente fruto de su participación en el movimiento de los países de América Latina que promovieron el Ecodesarrollo, que se explicó anteriormente. De la misma forma, se identifica el abordaje de la gestión del riesgo ante los desastres naturales en especial en los países centroamericanos y otros países más sensibles que incluyeron la dimensión social, el patrimonio cultural, la propiedad ancestral de la tierra como es el caso de Ecuador, que lo hizo desde su constitución política.

\section{Balance sobre la dimensión ambiental del ordenamiento del territorio colom- biano}

Como se observó en el análisis anterior, los lineamientos europeos planteados en la CEOT, a su vez fueron asumidos por la mayor parte de países en América Latina y el caso de Colombia no fue la excepción. A continuación, se presenta un balance general de la dimensión ambiental del ordenamiento del territorio colombiano, desde tres aspectos: La normatividad, las propuestas de las entidades competentes y finalmente los aportes conceptuales de algunos autores.

\section{Balance sobre la dimensión ambiental del ordenamiento del territorio colom- biano desde la normativa}

En primer lugar, la Constitución Política de 1991 brindó a Colombia los fundamentos sobre: los derechos del ambiente (Título 2, Capítulo 3), 
la organización del territorio (Título XI), y la planeación del desarrollo (Título XII, Capítulo 2 ), entre muchos otros aspectos. De la misma manera, en la primera parte de la década de los noventa en nuestro país, se dio el auge de la planeación y se crearon la mayor parte de Ministerios que lideran estos temas. Fruto de ello, son una serie de leyes sectoriales relacionadas con: el desarrollo sostenible, el desarrollo económico y social, y, el desarrollo territorial y urbano. Las cuales se presentan a continuación en orden cronológico:

- La Ley 99 de 1993, Ley General Ambiental, por la cual se crea el Ministerio del Medio Ambiente, se reordena el Sector Público encargado de la gestión y conservación del medio ambiente y los recursos naturales renovables, se organiza el Sistema Nacional Ambiental, SINA y se dictan otras disposiciones. Esta Ley en su Art. 1, dentro de los fundamentos de la política ambiental colombiana señala, que "el proceso de desarrollo económico y social del país se orientará según los principios universales y del desarrollo sostenible contenidos en la Declaración de Río de Janeiro de junio de 1992 sobre Medio Ambiente y Desarrollo" (Congreso de Colombia, 1994, p. 1).

- La Ley 152 de 1994. Ley orgánica del Plan de Desarrollo cuyo propósito es establecer los procedimientos y mecanismos para la elaboración, aprobación, ejecución, seguimiento, evaluación y control de los planes de desarrollo" (Congreso de Colombia, 1994, p. 1), además regula la planificación económica y social colombiana.

- La Ley 388 de 1997, Ley de Desarrollo Territorial y urbano, la cual surge como complemento a la planificación económica y social con la dimensión territorial.

- La Ley 1454 de 2011, llamada Ley Orgánica de Ordenamiento Territorial (LOOT). Luego de múltiples intentos fallidos, desde que se contemplara su elaboración en la Constitución del 91.
De acuerdo con lo aquí expuesto y como se observa en la figura 1, el ordenamiento territorial en el caso colombiano está asociado, más que una única política pública ${ }^{6}$ propia sobre el ordenamiento territorial, a un conjunto de leyes sectoriales, principalmente sobre: el desarrollo sostenible (Ley 99/93), el desarrollo económico y social (Ley $152 / 94$ ), y, el desarrollo territorial y urbano (Ley 388/97), que en su conjunto, con las políticas públicas sectoriales; brindan orientaciones, principios, conceptos y parámetros, muchos de ellos relacionados con el ordenamiento del territorio colombiano desde diferentes dimensiones.

Por otra parte, como se observa en la Imagen 3, la normativa ambiental en el caso colombiano ha tenido bastantes desarrollos con antecedentes tempranos, que condujeron de manera rápida a la consolidación de un Ministerio de Ambiente y a la propuesta inicial de un Ordenamiento Ambiental del Territorio (OAT). Este acontecimiento fue previo a la normativa relacionada con el desarrollo territorio (Ley 388/97) y mucho más a la relacionada con el ordenamiento del territorio (Ley 1454/2011). Aunque la Constitución Nacional lo demandara desde el año 1991.

En efecto, la Ley 99 de1993 propone el concepto de Ordenamiento Ambiental del Territorio alusivo a "la función atribuida al Estado de regular y orientar el proceso de diseño y planificación de uso del territorio y de los recursos naturales renovables de la Nación, a fin de garantizar su adecuada explotación y su desarrollo sostenible" (art. 7). De igual manera, asume el desarrollo sostenible como: "el que conduzca al crecimiento económico, a la elevación de la calidad de la vida y al bienestar social, sin agotar la base de

6 Un política pública es "un conjunto conformado por uno a varios objetivos colectivos considerados necesarios o deseables y por medios y acciones que son tratados, por lo menos parcialmente, por una institución u organización gubernamental con la finalidad de orientar el comportamiento de actores individuales o colectivos para modificar una situación percibida como insatisfactoria o problemática" (Roth, 2002, p. 27). 
Figura 1. Pilares del ordenamiento del territorio colombiano.

Constitución

Política de

1991. Art. 151

\section{Ordenamiento del territorio Colombiano}

\begin{tabular}{|c|}
\hline $\begin{array}{c}\text { Ordenamiento del } \\
\text { territorio Colombiano }\end{array}$ \\
\hline
\end{tabular}

"Carta Europea de Ordenamiento Territorial (1983)" se definió el OT como, "la expresión espacial de las políticas económicas, sociales, culturales y ecológicas de la sociedad”.

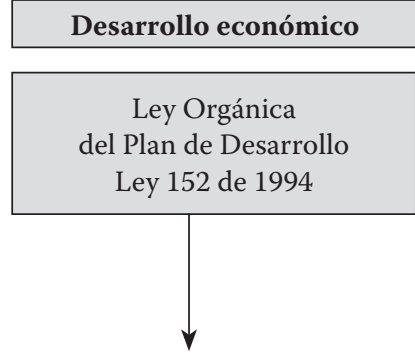

Planes de desarrollo 4 años Nacional Departamental Municipal

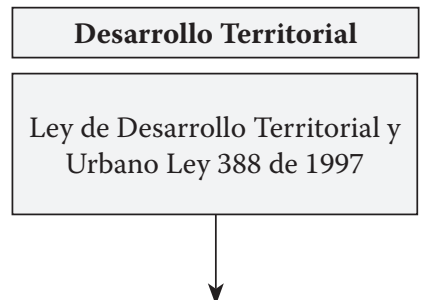

Planes de Ordenamiento Territorial (DNP, 2016) PBOT-EOT-POT a 10 años POT Municipal POD Departamental PMOT Metropolitanos Art. 24 Revisión CAR
Decreto 2278/53 ordena el uso y aprovechamiento de los bosques colombianos.

Ley 2/59 Delimita 7 Zonas Forestales

Decreto Ley 2811/74, Código de Recursos Naturales Renovables

Desarrollo Sotenible-92 Río

Ley 99 de 1993

Crea el Ministerio del Medio Ambiente, reordena el sector Público encargado de la gestión y conservación del medio Ambiente y los recursos naturales renovables, Organiza el SIstema Nacional Ambiental SINA y se dictan otras disposiciones

Decreto 1200 de 2004 - Instrumentos de Planificación Ambiental

\begin{tabular}{|c|c|}
\hline \multicolumn{2}{|c|}{$\begin{array}{c}\text { Decreto } 1200 \text { de } 2004 \text { - Instrumentos } \\
\text { de Planificación Ambiental }\end{array}$} \\
\hline Planes de Gestión Ambiental & $\underset{\text { SIGAM }}{v}$ \\
\hline Planes de Manejo Ambiental & S1G \\
\hline Regional 10 años o más PGAR & PGAR \\
\hline Planes de Acción Trienal- PAT & PMA \\
\hline Planes de Acción Cuatrienal - PACA & PACA \\
\hline amiento de & POMCA \\
\hline
\end{tabular}

Decreto 1729 de 2002 ordenamiento de cuencas

Enfoque técnico ambiental - la unidad de OT es la CUENCA- unidades de uso del suelo, temas ambientales como: sistema orográfico, sistema hidrogáfico, sistema de áreas protegidas, biodiversidad y cobertura vegetal, zonas de riego, y usos de suelo. En 2005- Inclusión de la gestión del riesgo y la vulnerabilidad ante los desastres naturales y el cambio climático.

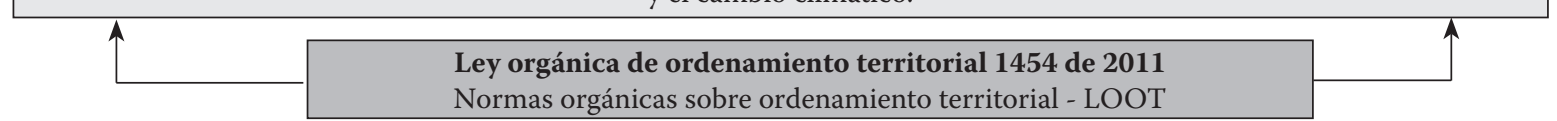

Fuente: Román (2016)

recursos naturales renovables en que se sustenta, ni deteriorar el medio ambiente o el derecho de las generaciones futuras a utilizarlo para la satisfacción de sus propias necesidades" (art. 3).

De otro lado, en la Ley 388 de 1997, se define el ordenamiento del territorio municipal el cual "comprende un conjunto de acciones político-administrativas y de planificación física concertadas, emprendidas por los municipios o distritos y áreas metropolitanas, en ejercicio de la función pública que les compete, dentro de los límites fijados por la Constitución y las leyes, en orden a disponer de instrumentos eficientes para orientar el desarrollo del territorio bajo su jurisdicción y regular la utilización, transformación y ocupación del espacio, de acuerdo con las estrategias de desarrollo socioeconómico y en armonía con el medio ambiente y las tradiciones históricas y culturales".

Asimismo, la Ley 388-97 provee los principios sobre los que se fundamenta el ordenamiento territorial colombiano (art. 2): 1). La función social y ecológica de la propiedad. 2). La prevalencia del interés general sobre el particular. 3). La distribución equitativa de las cargas y los beneficios. Así como, la declaratoria de la "función pública del ordenamiento territorial" (art. 3); función indelegable y ejercida por el Estado (gobiernos municipales y distritales) en conjunto con el privado, a través de acciones urbanísticas (deci- 
siones) y actuaciones urbanísticas (ejecuciones). Al igual que las posibilidades de concertación y participación en la planeación de desarrollo del territorio (art. 4), que, sin embargo, no son garantes del proceso.

Desde luego, el OT contempla acciones político-administrativas en un proceso de descentralización tanto de competencias, como de poder de decisión desde el orden nacional al local, donde los municipios son autónomos para decidir y regular el uso, ocupación y transformación de su territorio. Por tanto, la Ley 388/97, dispone que el ordenamiento territorial de los municipios y distritos se realice a través de Planes de Ordenamiento Territorial (POT) en desarrollo del art. 41 de la Ley 152 de 1994. En este sentido, la Ley 388 de 1997 en su art. 9 define el POT como "el conjunto de objetivos, directrices, políticas, estrategias, metas, programas, actuaciones y normas adoptadas para orientar y administrar el desarrollo físico del territorio y la utilización del suelo".

En cuanto a los POT, Massiris (1999) afirma que:

[...] ha primado la confusión y el caos en la formulación del primer plan de OT municipal, quizás, por establecerse primero la regulación jurídica, sin que existieran procesos generalizados de OT en estas entidades. Lo normal es que las leyes y normas legales surjan por la necesidad de regular procesos ya existentes. En el caso del OT no ha ocurrido así, por lo contrario, han sido las normas (Ley 152/94 y 388/97) las que han desencadenado los procesos que actualmente vivimos, tomando, como es lógico, a nuestros alcaldes sin preparación alguna. La norma no previó un período de transición, no menor a dos años, en el cual se produjeran y transfirieran las bases conceptuales, metodológicas e instrumentales que requiere la elaboración de planes de OT, para luego proceder a su formulación, proceso que debía tener un plazo no inferior a otros dos años.

Finalmente, la LOOT define el ordenamiento territorial en su art. 1 como: ...un instrumento de planificación y de gestión de las entidades territoriales y un proceso de construcción colectiva de país, que se da de manera progresiva, gradual y flexible, con responsabilidad fiscal, tendiente a lograr una adecuada organización político administrativa del Estado en el territorio para facilitar el desarrollo institucional, el fortalecimiento de la identidad cultural y el desarrollo territorial, entendido este como desarrollo económicamente competitivo, socialmente justo, ambientalmente y fiscalmente sostenible, regionalmente armónico, culturalmente pertinente, atendiendo a la diversidad cultural y físico-geográfica de Colombia. La finalidad del ordenamiento territorial es promover el aumento de la capacidad de descentralización, planeación, gestión y administración de sus propios intereses para las entidades e instancias de integración territorial, fomentará el traslado de competencias y poder de decisión de los órganos centrales o descentralizados de gobierno en el orden nacional hacia el nivel territorial pertinente, con la correspondiente asignación de recursos. El ordenamiento territorial propiciará las condiciones para concertar políticas públicas entre la Nación y las entidades territoriales, con reconocimiento de la diversidad geográfica, histórica, económica, ambiental, étnica y cultural e identidad regional y nacional.

\section{Balance sobre la dimensión ambiental del ordenamiento del territorio colombiano desde la institucionalidad}

En Colombia, la inclusión de la dimensión ambiental en el ordenamiento territorial desde el paradigma del desarrollo sostenible se llevó a cabo, a través de la iniciativa liderada por el Ministerio de Ambiente de proponer un ordenamiento ambiental territorial desde la Ley 99 /93, que:

[...] es "un componente fundamental, ineludible $e$ indisociable del ordenamiento territorial" (DNP y otros, 1996). La orientación de los procesos de uso y ocupación del territorio deberá ser evaluada considerando los impactos 
e implicaciones en los ecosistemas; el OAT suministra al OT una síntesis de la estructura y dinámica de los ecosistemas, una valoración de los principales conflictos y potencialidades y las diferentes propuestas de alternativas de uso, actividades y programaciones en el marco de la sostenibilidad. El punto de contacto de los procesos de OT y OAT está en la planificación del uso del territorio, como factor básico para avanzar hacia el desarrollo sostenible (Andrade, 1996, citado por Ministerio de Medio Ambiente, 1998, p. 8).

Posteriormente, dicha iniciativa es trasladada a los conceptos, principios y objetivos del desarrollo territorial colombiano, a través de la Ley 388 de 1997 en su art. 10, reglamentado por el Decreto Nacional 2201 de 2003, el cual contiene las determinantes del OT, que son normas de superior jerarquía y hacen referencia: a. determinantes ambientales (conservación y protección del ambiente, de los recursos naturales y la prevención del riesgo); b. determinantes en patrimonio (conservación preservación y uso del patrimonio cultural, histórico y arquitectónico), c. determinantes en infraestructura (nacional y regional- vial, puertos y aeropuertos, abastecimiento de agua, saneamiento y suministro de energía), y, d. componentes de OT en planes integrales de desarrollo metropolitano.

Así mismo, dentro de las determinantes ambientales se incluye:

- Aspectos ambientales en la zonificación de uso adecuado del territorio y uso del suelo.

- Conservación, preservación, uso y manejo del medio ambiente y de los recursos naturales renovables, en las zonas marinas y costeras.

- Reserva, alindamiento, administración o sustracción de los distritos de manejo integrado, los Distritos de conservación de suelos, las reservas forestales y parques naturales de carácter regional.

- Manejo de las cuencas hidrográficas.

- Conservación de las áreas de especial importancia ecosistémica.
- Sistema de parques nacionales naturales y las reservas forestales nacionales.

- Prevención de amenazas y riesgos para asentamientos humanos y zonas expuestas a amenazas y riesgos naturales (Paredes, 2013).

Sin embargo, estas determinantes ambientales están reglamentadas por el Sistema Nacional Ambiental- SINA, de acuerdo con la Ley 99 de 1993 y el Código de los Recursos Naturales. Igualmente, la Corporación Autónoma Regional o la Autoridad Ambiental de cada jurisdicción trabajan en garantizar el uso adecuado del territorio y el aprovechamiento sostenible de los recursos naturales renovables. Por tanto, las determinantes ambientales se consideran "como lineamientos generales de planificación que garantizarán la inclusión de los aspectos ambientales y la reglamentación de uso y ocupación del territorio dentro los instrumentos de Ordenamiento Municipal y demás actividades de planificación ambiental en los niveles regional y local" (Corpoamazonía, 2016, párrafo 5).

Los Determinantes Ambientales son un insumo importante para lograr la articulación de los procesos de revisión, ajuste y reformulación de los Planes de Ordenamiento Territorial con las propuestas de Ordenamiento Ambiental promovidas desde los niveles regionales y nacionales, como lo son las áreas protegidas, los Planes de Ordenación Forestal, Planes de Manejo de Páramos y Humedales, los Planes de Ordenación y Manejo de Cuencas y demás instrumentos de planificación existentes (Corpoamazonía, 2016, párrafo 6).

Con el mismo propósito, la Ley 388 de 1997 en su art. 24 determina que el POT cuente con una revisión por parte de la autoridad ambiental, es decir Ministerio de Ambiente, Vivienda y Desarrollo Territorial, de las Corporaciones Autónomas Regionales y de las Autoridades Ambientales Urbanas para el componente urbano de los centros poblados de más de un millón de habitantes.

Este último aspecto marca la diferencia, ya que dicho proceso de revisión llevó al entonces Minis- 
terio de Ambiente, Vivienda y Desarrollo Territorial a realizar aportes conceptuales desde un enfoque Técnico Ambiental, el que posteriormente se reflejó en sus publicaciones institucionales Guía para la formulación del Plan de Ordenamiento Territorial. Según las indicaciones de la autoridad ambiental se considera como unidad de ordenamiento del territorio a la cuenca hidrográfica y plantea como unidades de uso, componentes físico geográficos como: hidrología, zonas de riesgo, áreas protegidas, biodiversidad, cobertura vegetal y usos del suelo. Estos temas ambientales son considerados como unidades de uso del suelo. En efecto, el ordenamiento de las cuencas en Colombia lo reglamenta el Decreto 1729 de 2002, mediante la formulación de los Planes de Ordenamiento y Manejo de la Cuenca- POMCA, de superior jerarquía ante el POT, no obstante, no es clara la armonización entre estos instrumentos.

Uno de los inconvenientes que se presenta entre el Ordenamiento Territorial y el Ordenamiento Ambiental del Territorio, tanto en Colombia, como en otros países, es que no siempre coinciden las unidades de análisis territorial que se plantean, ya que en el OT colombiano la Ley 388/97 delega esta función a los Municipios y Distritos. A diferencia del Ordenamiento Ambiental, como se explicó anteriormente, ya que la unidad de ordenamiento del territorio, puede en este caso, corresponder a una cuenca hidrográfica o a un área protegida. Las cuales, en consecuencia, pueden abarcar varios municipios o unidades político-administrativas mayores como varios departamentos. Esta situación genera conflictos sociales y ambientales, poca efectividad de las políticas en el contexto real y una escasa visión integral sobre el ordenamiento del territorio. De la misma manera, este aspecto se identificó en el ordenamiento territorial de Chile:

Generalmente, los límites territoriales para efectos de la planificación se determinan a partir de divisiones administrativas porque se planifica para el espacio de una comuna o una región. Esta forma de delimitación, desde la perspectiva ambiental, no siempre favorece procesos de ocupación sustentable del territorio ya que las unidades definidas administrativamente pueden no ser coincidentes con las delimitaciones de las unidades ambientales -de carácter natural como una cuenca hidrográfica o de índole cultural como un área de desarrollo indígenalas que, en estos casos, corren el riesgo de quedar fragmentariamente sujetas a diferentes normalizaciones que pueden afectar su integridad física o cultural. De esta circunstancia surge la importancia de interrelacionar a los instrumentos de planificación en sus diferentes niveles de competencia o la necesidad de promover el desarrollo de planes que abarquen ambientes definidos como es el caso de las cuencas hidrográficas (Muñoz, 2003, p. 65).

Estos aspectos descritos anteriormente son fáciles de analizar, por ejemplo, en la cuenca del río Bogotá, la del río Magdalena o cuencas urbanas como la del río Tunjuelo que atraviesa a Bogotá. En el caso del río Tunjuelo, nace en la Laguna de los Tunjos, donde termina el páramo de Sumapaz, en la Localidad de Sumapaz (Imagen 4), con los Ríos Chisacá, Curubital y Mugroso conforman la cuenca alta. A esta altura ya se identifican los problemas que ejerce la frontera agrícola y ganadera en el Subpáramo a la altura de la Zona rural

Imagen 4. Laguna de los Tunjos, Páramo de Sumapaz. Nacimiento del río Tunjuelo donde termina el páramo de Sumapaz, en la Localidad de Sumapaz a una hora de Usme.

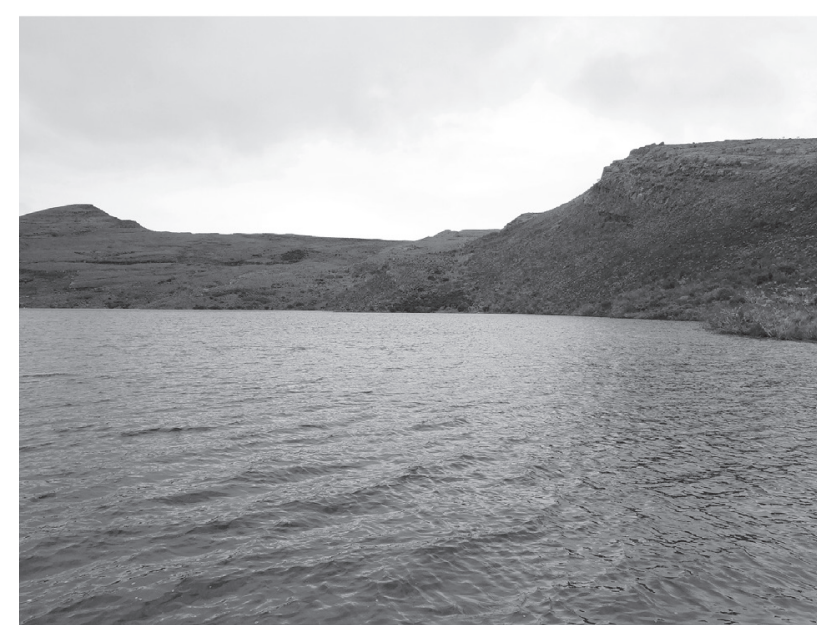

Fuente: fotografía tomada por la autora en 2014. 
de Usme (Imagen 5). Así mismo, se registran actividades mineras cerca al páramo. Luego, se observa la afectación de urbanizaciones legales o ilegales sobre el río con el vertimiento de aguas negras. Aquí ya el río se torna turbio y se observa contaminado (Imagen 6); no obstante, conserva la vegetación en su cauce. Finalmente, luce un río muerto (Imagen 7), luego de su paso por las curtiembres en la Zona de San Benito, así como de la actividad minera de extracción de piedra y grava por parte de nacionales y multinacionales en la localidad de Tunjuelito, y su entrada a la zona del matadero en la Localidad de Kennedy, para desembocar en la localidad de Bosa en la cuenca media del río Bogotá, donde sus aguas se utilizan en el riego de productos agrícolas, locales y rurales.

En el mismo sentido, en el año 2005 la Dirección de Desarrollo Territorial del Ministerio de Ambiente, Vivienda y Desarrollo Territorial, con el apoyo del Departamento Nacional de Planeación a través del Programa para la Reducción de la Vulnerabilidad Fiscal del Estado ante Desastres Naturales elaboró la Guía metodológica Incorporación de la Prevención y la Reducción de Riesgos en los Procesos de Ordenamiento Territorial; publicaciones del MAVDT dirigidas a fortalecer los procesos de Ordenamiento Territorial y de Desarrollo Regional

Imagen 5. Presión de la frontera agrícola y ganadera sobre le Subpáramo. Zona de reserva y zona rural Límites localidad de Sumapaz y Usme.

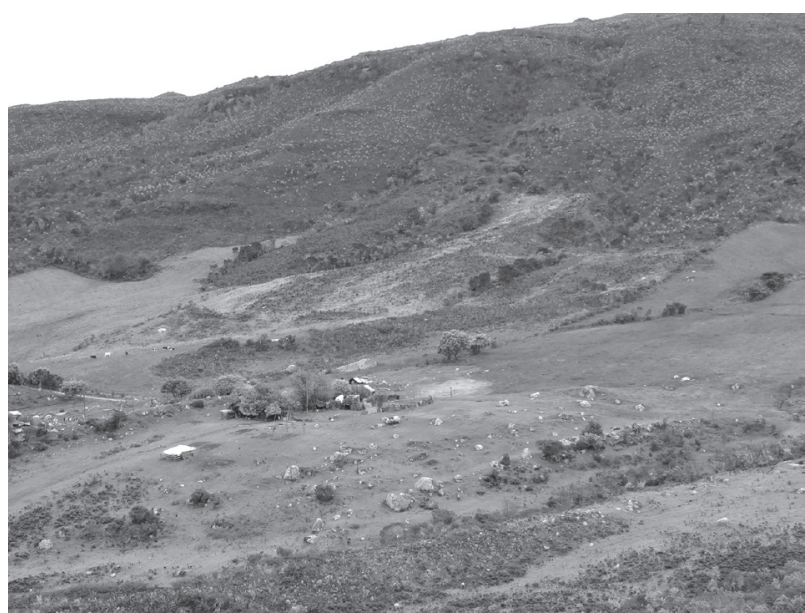

Fuente: fotografía tomada por la autora en 2014.
Imagen 6. Contaminación por vertimientos de urbanizaciones legales e ilegales sobre el río Tunjuelo a la altura de la Localidad de Usme.

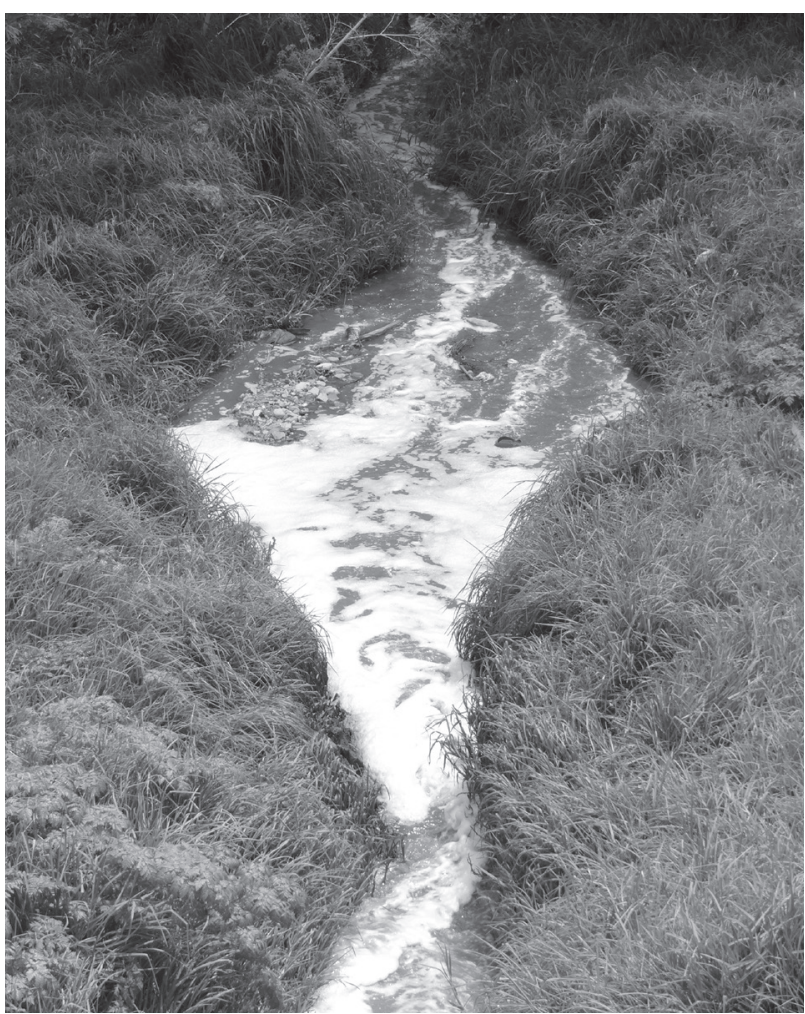

Fuente: fotografía tomada por la autora en 2014.

Imagen 7. Río Tunjuelo a la altura del frigorífico Guadalupe en la localidad de Kennedy, luego de pasar por la zona de curtiembres y explotación minera en la Localidad de Tunjuelito. Se observa un río muerto a pocos kilómetros de su desembocadura en el río Bogotá en la localidad de Bosa.

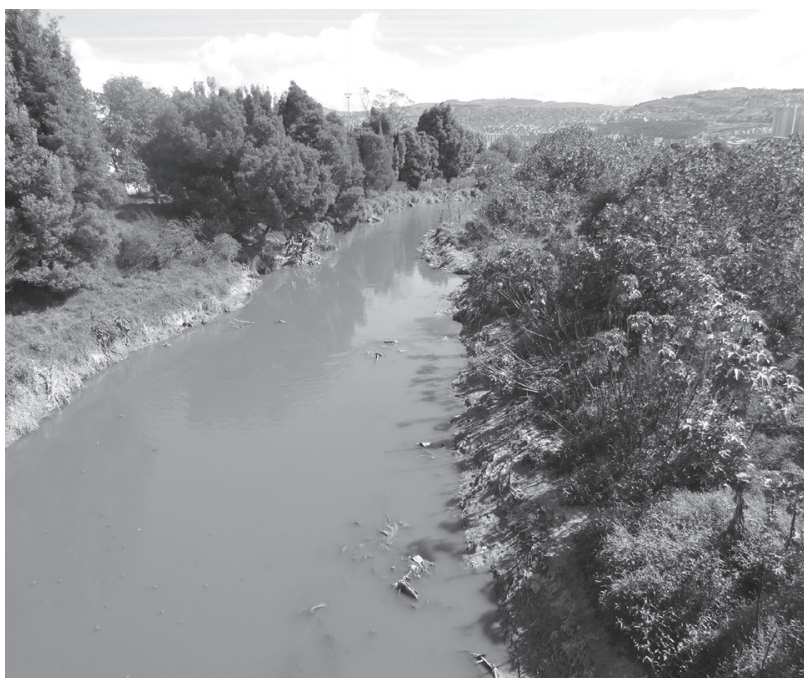

Fuente: fotografía tomada por la autora en 2014. 
en el país, y tiene por objetivo dar a conocer a los funcionarios, instituciones y comunidad en general las herramientas básicas para incorporar de una forma técnica y adecuada, la Prevención y Reducción de Riesgos en los procesos de Ordenamiento Territorial, Planes de Desarrollo y de Planificación Regional y Sectorial.

El actual Ministerio de Ambiente y Desarrollo Sostenible desde su oficina de Ordenamiento Ambiental Territorial trabaja no sólo por fortalecer el componente ambiental dentro del ordenamiento territorial, además su gestión está orientada a la inclusión de Incorporación de la Prevención y la Reducción de Riesgos, así como el Cambio Climático en los Procesos de Ordenamiento Territorial, ante la situación actual mundial y las últimas temporadas de lluvias en nuestro país.

\section{Balance sobre la dimensión ambiental del ordenamiento del territorio desde algunos autores}

En primer lugar, Massiris considera que el Ordenamiento Territorial:

se trata de una política de Estado y un proceso planificado de naturaleza política, técnica y administrativa, cuyo objeto central es el de organizar, armonizar y administrar la ocupación y uso del espacio, de modo que éstos contribuyan al desarrollo humano ecológicamente sostenible, espacialmente armónico y socialmente justo". Donde [...] "confluyen las políticas ambientales, las políticas de desarrollo regional, espacial o territorial y las políticas de desarrollo social y cultural, cuya naturaleza es determinada por el modelo de desarrollo económico dominante en cada país (Massiris, 2010).

Por ejemplo, Massiris realizó algunos aportes, al igual que apreciaciones importantes y visionarias sobre el ordenamiento territorial, ya que logró fusionar los dos enfoques tradicionales del ordenamiento territorial (el enfoque pasivo - planeación física-, con el enfoque activo -planeación económica y social-). Sin embargo, lo más significativo de sus trabajos, es la presencia de la dimisión ambiental desde un enfoque que orienta de manera preventiva el desarrollo hacia un urbanismo que busque la sostenibilidad de las ciudades como se observa a continuación:

En el OT el espacio pierde el carácter pasivo propio de la visión sectorial, para convertirse en estructurante de los objetivos, las políticas y las acciones públicas y privadas, tanto sectoriales como territoriales. Se trata, en este caso, de articular los objetivos económicos, sociales, ambientales y administrativos con el territorio, racionalizar las actuaciones sobre éste y orientar previsoriamente su desarrollo y aprovechamiento sostenible, basado, especialmente, en estrategias de uso, ocupación y manejo del territorio y de desarrollo territorial (Ortíz \& Massiris, 1993).

Adicionalmente, el mismo autor identifica el ordenamiento territorial como una estrategia para reorientar a los países latinoamericanos hacia un desarrollo sostenible en una reivindicación ambiental y social con el territorio:

En conjunto con la creciente conciencia de la irracionalidad de los modelos económicos desarrollistas y la búsqueda de alternativas de desarrollo sostenibles, han estimulado la adopción del ordenamiento territorial como estrategia de los estados para armonizar las actividades humanas con el aprovechamiento de los recursos naturales y con la distribución social y regional equilibrada de los beneficios de tales actividades. Se trata de intervenir, de manera voluntaria, el orden territorial injusto y desordenado, creado de manera espontánea por las fuerzas económicas; para inducir la construcción de escenarios deseados desde el punto de vista ambiental, social y espacial (Massiris, 1991).

Por otra parte, autores como Prieto y Luengas (s.f.), proponen que la LOOT sea un "instrumento jurídico que permita una integración entre el ordenamiento territorial y ambiental de los municipios de Colombia, a partir de cuatro puntos críticos identificados: a) Uso insostenibles del territorio y 
transformación de los ecosistemas; b) Crecimiento urbano; c) Ocupación de áreas de alto valor ecosistémico y cultural, y d) Deterioro y disminución de la oferta hídrica. Los autores afirman que:

Esta integración es urgente y necesaria. Sin embargo, a la luz de una nueva Ley Orgánica de Ordenamiento Territorial, las consideraciones medioambientales no son tenidas en cuenta. La legislación en Colombia sigue estando netamente preocupada por la repartición del territorio y así mismo por los beneficios medio ambientales que de este se pueda obtener, como es el caso del énfasis que prevalece sobre el reparto y administración de las regalías en Colombia. No se establecen criterios y políticas claras de conservación y preservación del medio ambiente (p. 17).

De la misma manera es importante recordar planteamientos tan importantes como los de Fals Borda (1998), quien estuvo en la primera COT, luego de la constitución del 91, y quien en su primera propuesta de LOOT, sugirió una reorganización político administrativa del Estado colombiano para la conformación de Provincias y Regiones, la cual por razones obvias no fue acogida, pero que, desde su definición de OT, contemplaba otras unidades diferentes a los Municipios:

[...] trata del manejo político-administrativo de los conjuntos humanos que ocupan espacios geográficos concretos, donde las comunidades ejercen funciones sociales ligadas a la economía, la cultura y el medio ambiente. En Colombia estos espacios sociogeográficos se definen como veredas o caseríos, corregimientos, municipios, áreas metropolitanas, distritos y departamentos, para conformar el ámbito unitario de la nación (Párrafo 7).

Sin embargo, frente a la diversidad de concepciones sobre ordenamiento territorial, es importante resaltar, por ejemplo, que para Borja (2000) "este concepto está en construcción en las ciencias sociales y en la acción política, y en el país, esa condición no es la excepción" (Citado por Carrión, 2008, p. 146). En este sentido, Massiris
(2002) afirma: "la ordenación del territorio es un concepto aún en construcción, de carácter polisémico, sujeto a diversas interpretaciones sin que exista una definición universal que satisfaga a todos" (párrafo 23). Con el mismo propósito, afirma Sáenz de Buruaga que "la Ordenación del Territorio resulta ser un concepto complejo, polifacético, relativo, pluridimensional, ambivalente, $y$, sobre todo, antropocéntrico, del que, ciertamente, puede decirse que está llamado a ser un reflejo palpable del grado de eficiencia y equidad adquirido por una determinada sociedad" (1980, p. 18, citado por Foy, 2009, p. 140) (Pérez, 1998, p. 19, citado por Cordero, 2011, p. 216).

No obstante, nuevos planteamientos surgen como el de Salinas (2013), que afirma:

Es necesario apuntar que la ordenación del territorio es el proceso público y técnico de la planificación y, por lo tanto, este debe ser flexible, continuo y a largo plazo, además de holístico y sistémico, ya que no solo es ambiental sino social, económico, político y administrativo, debiendo traducirse en una zonificación de las capacidades potenciales del territorio (oferta u objeto de la planificación), para acoger determinada actividad socioeconómica (demanda o sujeto de la planificación) y que permita encontrar soluciones para los principales problemas y conflictos presentes en el territorio (p. 146).

Finalmente, Massiris plantea retos a futuro para el Ordenamiento territorial desde una concepción más holística e interdisciplinaria:

Dentro de este contexto, el OT trasciende su consideración de apéndice o complemento de las políticas de desarrollo económico para convertirse en un nuevo enfoque, un nuevo estilo de planificación, un nuevo sistema de valores, o una utopía, en la que la visión sectorial y economicista del desarrollo, cede su paso a una visión integral, humanista y prospectiva, en la cual las políticas económicas incorporan los valores de sostenibilidad ambiental, equilibrio regional y bienestar social (Massiris, 2010). 


\section{Conclusiones}

En cuanto a la inclusión de la dimensión ambiental en el ordenamiento territorial en el mundo, es posible identificar su abordaje en los contenidos desde la primera Carta Europea de Ordenamiento Territorial (CEOT), la cual contempló desde su origen la interrelación hombre-naturaleza, al igual que la dimensión ambiental y social como propias del ordenamiento del territorio; y las estrategias de integración, coordinación y participación como objetivos desde un ejercicio político. Probablemente, esto se dio como consecuencia de la inclusión de la dimensión ambiental en el desarrollo económico producto de los manifiestos ambientales que se iniciaron en los $60 \mathrm{~s}$, como los del Club de Roma y su informe sobre los Límites del Crecimiento, y posteriormente, con mayor fuerza con el surgimiento del paradigma del desarrollo sostenible.

En el caso de los países de América Latina existe un hecho relevante y poco reconocido, es la propuesta del Ecodesarrollo en los años 70. Como se demostró en este escrito no fue atractiva para los países desarrollados posiblemente porque daba autonomía a los países latinoamericanos en la explotación y conservación de sus recursos. $\mathrm{Al}$ igual, los países de América Latina propusieron dos décadas después, el informe: Nuestra Propia Agenda sobre Desarrollo y Medio Ambiente (1990), donde se propuso el ordenamiento del territorio como una de las estrategias para el desarrollo sostenible de los países latinoamericanos. No obstante, para muchos el paradigma del desarrollo sostenible se traduce en un oxímoron ${ }^{7}$, que en la práctica resulta bastante complejo bajo el modelo de desarrollo imperante, puesto que los resultados no son alicientes frente a una población que en 2016 sobrepasó los siete mil millones de habitantes, una crisis socio-ambiental del planeta irreversible y un cambio climático innegable que

\footnotetext{
7 “Combinación en una misma estructura sintáctica de dos palabras o expresiones de significado opuesto, que originan un nuevo sentido" (RAE, 2012).
}

afecta a todos, al igual que unos recursos naturales cada vez más escasos, así como una mayor desigualdad, inequidad y pobreza.

Estas evidencias permiten afirmar que dese América latina se han liderado varias iniciativas relacionadas con el desarrollo y con la sostenibilidad llevadas a la agenda mundial, las cuales han terminado diluyéndose en los tratados finales. Pero es en América Latina donde se encuentra la mayor biodiversidad mundial, la riqueza cultural y el poder emancipador que lleva al siguiente cuestionamiento: ¿un desarrollo sostenible para qué? o ¿para quién? Si los países industrializados causantes de la mayor contaminación no tiene ninguna intención en promover un cambio, ¿Es posible pensar en otras formas de desarrollo?, o retomar algunos planteamientos de décadas atrás como lo fue el ecodesarrollo?

El ordenamiento territorial en el caso colombiano está asociado, más que una única política pública propia sobre el ordenamiento territorial, a un conjunto de leyes sectoriales sobre aspectos como: el desarrollo sostenible (Ley 99/93), el desarrollo económico y social (Ley 152/94), y, el desarrollo territorial y urbano (Ley 388/97), lideradas desde diferentes Ministerios. En el mismo sentido, son estas leyes y sus políticas públicas sectoriales las que brindan orientaciones, principios, conceptos y parámetros muchos de ellos relacionados con el ordenamiento del territorio. Estas leyes sectoriales se instrumentalizan a través de la formulación de planes desarticulados, de poca efectividad y descontextualizado con la realidad en lo local, posiblemente por su enfoque Top down (arriba hacia abajo), aunque se contemplen principios e instrumentos de concertación y participación dentro de las mismas. Por tanto, se cuestionan sus resultados, por ejemplo, frente al estado de los recursos naturales y a la calidad de vida de las minorías donde se evidencia una inasistencia del Estado.

En definitiva, en Colombia han permeado las concepciones y lineamientos internacionales $y$ 
latinoamericanos, tanto del desarrollo sostenible, como del ordenamiento territorial. Por un lado, se identifica una propuesta de lineamientos sobre el Ordenamiento Ambiental Territorial- OAT (Ley 99/93) y por el otro de Desarrollo Territorial (Ley 388/97). El OAT en la práctica se convierte en la exigencia de unas determinantes ambientales relacionadas con: la zonificación del suelo, el manejo de las áreas protegidas y los parques naturales, el manejo de la cuenca, la conservación de los ecosistemas y la definición de las zonas de riesgo natural. Aunque estas determinantes ambientales son muy importantes para el ordenamiento del territorio, es necesario vincular a todos los actores en los procesos participativos y en el ejercicio de definición de políticas bottom up (de abajo hacia arriba), que dinamice la dimensión social y ambiental del ordenamiento territorial.

Al respecto, se identifican algunas iniciativas del Ministerio de Ambiente relacionadas con el ordenamiento ambiental de humedales y de áreas protegidas, no obstante, aún no se armonizan con los instrumentos del ordenamiento territorial en la práctica, posiblemente sean una buena alternativa las figuras propuestas en la LOOT las que permitan esta integración entre el OAT y el OT, acordes a las dinámicas del contexto y a la realidad.

En síntesis el ordenamiento del territorio es un deber del Estado, es una cuestión política y es un asunto de poder, por tanto es necesario, por parte del Estado colombiano, asumir el reto de explorar nuevos enfoques híbridos de políticas (Top down y bottom up), donde se venzan las divisiones político administrativas del espacio geográfico y posibiliten un ordenamiento sostenible del territorio, el cual debe propender por la armonización de la dimensión natural, social y económica, y que muy seguro, en la práctica serán tangibles a través de las figuras propuestas en la LOOT (Ley 1454/2011), como el desarrollo de proyectos conjuntos entorno a un tema común de región y no de municipio.

\section{Referencias bibliográficas}

Alfonzo I. (1994). Técnicas de investigación bibliográfica. ( $7^{\mathrm{a}}$ ed.). Caracas, Venezuela: Contexto editores.

Andrade, A. (1996) "Ordenamiento Ambiental Territorial y Gestión Ambiental". En Ministerio del Medio Ambiente - CIDER. El Ordenamiento Ambiental del Territorio. Panel de Expertos. Memorias. Sasaima.

Camargo, G. (2005). Ciudad ecosistema: Introducción a la ecología urbana. ( $1^{\text {a }}$ ed). Bogotá, Colombia: DAMA -Universidad Piloto de Colombia.

Carta Europea del Ordenación del Territorio. (1983). Consejo de Europa. [En línea] Torremolinos. España. Recuperado el 21 de agosto de 2011 de: [http://titulaciongeografia-sevilla.es/web/contenidos/profesores/ materiales/archivos/Carta_Europea_OT[1].pdf].

Carrión, G. (2008). “Debilidades del nivel regional en el ordenamiento territorial colombiano. Aproximación desde la normatividad política administrativa y de usos del suelo". En: Arquitectura, Ciudad y Entorno (Universidad Politécnica de Cataluña. Año III, núm. 7, junio 2008). [En línea] Recuperado el 16 de agosto de 2011 de: [http://upcommons.upc.edu/bitstream/ handle/2099/5648/9_GUSTAVO-CARRION.pdf; sequence $=1]$.

Congreso de Colombia. Ley 99 de 1993, Ley General Ambiental, por la cual se crea el Ministerio del Medio Ambiente, se reordena el Sector Público encargado de la gestión y conservación del medio ambiente y los recursos naturales renovables, se organiza el Sistema Nacional Ambiental, SINA, y se dictan otras disposiciones. [en línea]. Recuperado agosto de 2010 de: [http://www.alcaldiabogota.gov.co/sisjur/normas/ Norma1.jsp?i=297].

Congreso de Colombia. Ley 152 de 1994, Ley orgánica del Plan de Desarrollo. [en línea]. Recuperado de: [http://www.alcaldiabogota.gov.co/sisjur/normas/Nor ma1.jsp?i=327].

Congreso de Colombia. Ley 388 de 1997, Ley de Desarrollo Territorial. En Diario Oficial año CXXXIII. No. 43091. 24, 1997. [en línea]. Recuperado de: [http:// www.dnp.gov.co/Portals/0/archivos/documentos/ DDTS/Gestion_Publica_Territorial/1bnormativida dley_388_1997.pdf].

Congreso de Colombia. Ley 1454 de 2011. Ley de Ordenamiento Territorial. Por la cual se dictan normas orgánicas sobre: ordenamiento territorial y se modifican 
otras disposiciones. [en línea]. Recuperado de:[http:// wsp.presidencia.gov.co/Normativa/Leyes/Documents/ ley145428062011.pdf].

Cordero Q.E. (2011). Ordenamiento territorial, justicia ambiental y zonas costeras Revista de Derecho (Valparaiso), núm. XXXVI. Valparaiso, Chile: Pontificia Universidad Católica de Valparaíso, pp. 209-249. Recuperado de: [http://www.redalyc.org/articulo.oa?id=17 3620958005].

Corpoamazonía (2016). Determinantes Ambientales. [en línea]. Recuperado febrero de 2016. [http://www. corpoamazonia.gov.co/index.php/ordenamiento-am biental/determinantes-ambientales].

Cuervo, L.M. (2006). Ordenamiento territorial: una reflexión desde la epistemología, la ética y la política. En Seminario "Ordenando nuestro territorio. Desafíos, definiciones y experiencias". Instituto de Estudios Urbanos y Territoriales de la Pontificia Universidad Católica de Chile, Santiago, diciembre 11 y 12 de 2006.

DNP et al. (1996). Fundamentos Sobre el Ordenamiento Territorial como Instrumento de Planificación. Santafé de Bogotá, D.C., marzo de 1996.

Elizalde, A. (2002). "Otro sistema de creencias como base y consecuencia de una sustentabilidad posible". En: Leff, E. (Coord.). Ética, vida, sustentabilidad. México: Programa de las Naciones Unidas para el Medio Ambiente. Red de Formación Ambiental para América Latina y el Caribe

Estermann, J. (2012). "Crisis civilizatoria y Vivir Bien”. Polis, 11 (33), 149-174. Recuperado de: [http:// www.scielo.cl/scielo.php?pid=S0718 -65682012000300 007\&script $=$ sci_arttext].

Foy, P. (2009). "Consideraciones jurídicas sobre el ordenamiento territorial ambiental". Espacio y Desarrollo $\mathrm{N}^{\circ}$ 21, 2009, pp. 139-169. Recuperado de: [https://dialnet. unirioja.es/descarga/articulo/ 5339553.pdf].

Handal, L., Bélanger, M., Montaño, C. y Nauro Viri, F. (Dir. Sauvé, L. y Orellana, I.). (2015). Ecodesarrollo comunitario. Módulo 1. Programa de formación de líderes en ecodesarrollo comunitario y salud ambiental. Proyecto Ecominga Amazónica. Montréal: Les Publications du Centr'ERE. Centro de investigación en educación y formación ambiental y ecociudadanía Université du Québec à Montréal Recuperado de: [http://www.ecominga.uqam. ca/PDF/modulo/modulo1.pdf].

Instituto de Investigación de Recursos Biológicos Alexander von Humboldt (2014). Principios y criterios para la delimitación de humedales continentales. Una Herramienta para fortalecer la resiliencia y la adaptación al cambio climático en Colombia. ( $1^{\text {ra }}$ Ed.). Bogotá.

Massiris, A. (1987). "Racionalidad espacial de la actual división político-administrativa de Colombia: Hacia una nueva regionalización departamental", tesis de grado para optar el título de Magister en Geografía, Convenio UPTC-IGAC.

Massiris, A. (1991). "Reflexión sobre una política de ordenación territorial en los países latinoamericanos: el caso de Colombia". En: Asociación Colombiana de Geógrafos, Trimestre Geográfico (Bogotá, No. 15, junio), pp. 3-23.

Massiris, A. (1993). "Bases Teórico-metodológicas para estudios de ordenamiento territorial“" En: Misión Local, Revista del Instituto de Desarrollo del Distrito Capital y la Participación Ciudadana y Comunitaria IDCAP, Santafé de Bogotá, Universidad Distrital, año 2, No. 2, enero/marzo, pp. 43-87.

Massiris, A. (1993a). "Geografía y regionalización". En: COLCIENCIAS, Colombia: ciencia y tecnología (Santafé de Bogotá, Vol. 10 No. 4, marzo), pp. 22-24.

Massiris, A. (1999). Ordenamiento territorial: experiencias internacionales y desarrollos conceptuales y legales realizados en Colombia. Ed. Planeta de Agostini. Disponible en: [http://www.elagrimensor.com.ar/elearning/ lecturas/ordenamiento\%20territorial.pdf].

Massiris, A. (2002), "Ordenación del territorio en América Latina", Scripta Nova, revista electrónica de geografía y ciencias sociales, 6(125). Recuperado de: http://www.ub.edu/geocrit/sn/sn-125.htm

Massiris, A. (2006). Políticas Latinoamericanas de ordenamiento territorial. Realidad y Desafíos. Universidad Pedagógica y Tecnológica de Colombia. ( $1^{\text {ra }}$ Ed.). Tunja. Boyacá.

Mayor, F. (2009). "Los límites del crecimiento". Temas para el Debate. Tribuna Libre, 181 Recuperado de: [http://www.fceco.uner.edu.ar/archivos/LIMITES\%20 AL\%20CRECIMIENTO\%202.pdf].

Ministerio de Ambiente y Desarrollo Sostenible (2012). Política Nacional de Gestión de la Biodiversidad y Servicios Ecosistémicos (PNGBSE). Bogotá. [en línea]. Recuperado junio de 2015. Disponible en: [http://www. humboldt.org.co/es/component/k2/item/646-pngibse? highlight=YToyOntpOjA7czo5OiJwb2zDrXRpY2EiO2 k6MTtzOjEwOiJwb2zDrXRpY2FzIjt9]. 
Ministerio de Medio Ambiente (1998). "Lineamientos para la política de Ordenamiento Ambiental territorial" (documento para discusión). Junio 1998. Recuperado de: [cdim.esap.edu.co/BancoMedios/.../lineamientos\%20 ordenamiento\%20ambiental.doc].

Muñoz, M. (2003). La dimensión ambiental en los instrumentos de planificación territorial Urbano, vol. 6, núm. 7, enero, 2003, pp. 63-72. Concepción, Chile: Universidad del Bío Bío. Recuperado de: [http://www. redalyc.org/articulo.oa?id=19800711].

Organización de Estados Iberoamericanos- OEI (2013). Boletín $\mathrm{N}^{\circ}$ 86. "La nueva ciencia de la Sostenibilidad: Un potente impulso para la transición a un futuro sostenible". Recuperado de: [http://www.rieoei.org/de loslectores/765Ojeda.PDF].

Páramo, P. (2010). Investigación documental y estado del arte. Presentación. Bogotá D.C.: Universidad Piloto de Colombia.

Paredes, G. (2013). “Áreas protegidas en determinantes de ordenamiento territorial. Recomendaciones para autoridades ambientales y entes territoriales para la contribución en la conservación efectiva de áreas protegidas desde los procesos de diseño, ajuste, aplicación y revisión de los determinantes de ordenamiento territorial”. Documento 3. Serie Áreas Protegidas y Ordenamiento Territorial. Parques Nacionales. Abril 2013. Recuperado de: [http://www.parquesnacionales.gov.co/ portal/wp-content/uploads/2015/07/\%C3\%81REASPROTEG ID A S - EN - D ET ERMINANTES - D E ORDENAMIENTO-TERRITORIAL.pdf].

Pierri, N. (2005). Historia del concepto de desarrollo sustentable. Recuperado de: [http://rimd.reduaz.mx/ coleccion_desarrollo_migracion/sustentabilidad/ Sustentabilidad5.pdf].

Prieto, J. y Luengas, E. (s.f.). "La ley orgánica de ordenamiento territorial, como instrumento para la integración del ordenamiento territorial y ambiental". Recuperado de: [http://www.umng.edu.co/documents /10162/745281/V3N2_24.pdf].

Red Colombiana de Formación Ambiental - RCFA (2007). Las ciencias ambientales: Una nueva área de conocimiento. ( $1^{\text {a }}$ ed). Bogotá, Colombia: Digiprint Editores.

Román, Y. (2016). Sistema Ambiental Universitario: Modelo integrado de gestión para la inclusión de la dimensión ambiental y urbana en la Educación Superior. (1 $1^{\text {a }}$ ed). Bogotá, Colombia: Universidad Piloto de Colombia.

Román, Y. \& Cuesta, O.J. (2016). Comunicación y conservación ambiental: avances y retos en Hipanoamérica. Revista Latina de Comunicación Social, 71, pp. 15-39. Recuperado de: [http://www.revistalatinacs org/071/paper/1082/02es.html].

Salinas. E. (2013) Reflexiones acerca del papel del ordenamiento territorial en la planificación y gestión ambiental. Perspectiva Geográfica, 18(1), pp. 141-156). Recuperado de: [http://revistas.uptc.edu.co/revistas/ index. php/perspectiva/article/view/2254].

UN. (1972). Declaración de Estocolmo sobre Medio Ambiente Humano. Adopción: Conferencia de las Naciones Unidas sobre el Medio Ambiente Humano, 16 de junio de 1972 Recuperado de: [http://www. ordenjuridico.gob.mx/TratInt/Derechos\%20Humanos/ INST\%2005.pdf].

ONU (2015). "Proyecto de documento final de la cumbre de las Naciones Unidas para la aprobación de la agenda para el desarrollo después de 2015". Anexo Transformar nuestro mundo: la Agenda 2030 para el Desarrollo Sostenible. 12 agosto, 2015. Recuperado de: [http:// www.un.org/es/comun/docs/?symbol=A/69/L.85].

Uribe, J. (2013). “La investigación documental y el estado del arte como estrategia de investigación en ciencias sociales". En: Páramo, P. (Comp.) La investigación en Ciencias Sociales: estrategias de investigación. 2 a ed. Bogotá: Universidad Piloto de Colombia.

Zoido, F. (1998). Geografía y ordenación del territorio. Scripta Vetera, Universidad de Barcelona, núm. 77. Disponible en: [http://www.ub.es/geocrit/sv-77.htm]. Reproducido de: Íber, Didáctica de las ciencias sociales. Geografía e Historia, Barcelona: núm. 16, abril 1998, pp. 19-31. 